\title{
A cultura material escolar na instrução primária no Maranhão oitocentista
}

\section{School material culture in primary education in the eighteenth century Maranhão}

\author{
Samuel Luis Velázquez Castellanos*
}

\begin{abstract}
RESUMO
O objetivo do artigo é problematizar os conteúdos que emergem de fontes documentais sobre a instrução primária no período imperial na Província do Maranhão à luz dos conceitos da teoria da cultura material escolar. Sustenta-se o estudo nos aportes teórico-metodológicos da História Cultural e operacionaliza-se em duas frentes: a revisão da literatura sobre a temática em questão e a localização, identificação e análise das fontes oriundas do Arquivo Público do Maranhão, que nos auxiliam na compreensão da cultura maranhense, da cultura escolar das instituições de ensino primário e da cultura material escolar por meio de leis, regulamentos, decretos, aprovações e veto. Verificam-se as ações dos presidentes da Província e dos inspetores sobre a instrução primária local expressa nos relatórios e ofícios, avaliando-se o poder da gestão nas decisões de abrir e fechar escolas, nomear e demitir professores, abrir concursos públicos, criar cadeiras e exigir métodos de ensino; práticas culturais específicas estabelecidas entre estratégias de imposição e táticas de apropriação. Analisam-se os atos que orientam o ensino primário e identificam-se concepções, práticas e posicionamentos referentes à instrução, possibilitando interpretações de signos, sentidos e significados que norteiam as práticas escolares e sociais numa abordagem pedagógica, sociológica e política como dimensão cultural das culturas escolares e da cultura material escolar segundo sua natureza e função.
\end{abstract}

Palavras-chave: Instrução Primária. Culturas escolares. Cultura material escolar. Maranhão Império.

${ }^{*}$ Universidade Federal do Maranhão. São Luís, Maranhão, Brasil. E-mail: samuel. velazquez@ufma.br - http://orcid.org/0000-0003-0849-348X 


\begin{abstract}
The aim of the article is to problematize the contents that emerge from documentary sources on primary education in the imperial period in Maranhão Province in the light of the concepts of the theory of school material culture. The study is supported by the theoretical-methodological contributions of Cultural History and is operationalized on two fronts: the literature review on the subject in question and the location, identification and analysis of sources from the Public Archive of Maranhão that help us understand the local culture, the school culture of primary education institutions and the cultural material school through laws, regulations, decrees, approvals and veto. The actions of the provincial presidents and the inspectors regarding the local primary education expressed in the reports and letters are verified, assessing the power of management in decisions to open and close schools, appoint and dismiss teachers, open competitions, set up chairs and demand teaching methods; specific cultural practices established between imposition strategies and appropriation tactics. We analyze the acts that guide primary education and identify conceptions, practices and positions regarding instruction, enabling interpretations of signs, meanings and meanings that guide school and social practices in a pedagogical, sociological and political approach as a cultural dimension of cultures and material culture according to their nature and function.
\end{abstract}

Keywords: Primary Instruction. School cultures. School material culture. Maranhão Empire.

\title{
Introdução
}

Neste artigo apresentam-se discussões sobre a instrução primária maranhense no século XIX na perspectiva da cultura material escolar, baseadas em fontes documentais. A intenção é garimpar atos e fatos nos registros que auxiliem a compreender as estratégias de imposição em uso que nortearam este nível de ensino na província a partir de leis e decretos imperiais e seus propósitos de licitude e consolidação; embora entenda que, mesmo com as prescrições que emanam das relações de força que pretenderam materializar desígnios hegemônicos dominantes, a escola como configuração singular também tem produzido e vem produzindo redes de significados a partir de táticas de apropriação que se refletem nas práticas diferenciadas dos sujeitos envolvidos num equilíbrio de tensões. Políticos, gestores, professores, alunos e familiares considerados aqui como fabricantes/consumidores de outra produção: a cultura escolar mediada pela cultura material da escola. 
Se os estudos sobre cultura escolar têm sido objeto de pesquisas em História da Educação, com a devida atenção ao cotidiano da escola e seu entorno, bem como aos agentes e profissionais que nela têm atuado direta e indiretamente, sobretudo quando inquiro os processos históricos relacionados às praticas escolares, então o conceito de cultura material da escola não poderia ser definido sem antes relacioná-lo com a cultura como produto humano. Nessa lógica, se levo em consideração o âmbito e as conjunturas da disposição do ensino público primário maranhense na primeira metade do século XIX e seu relativo crescimento para a época, os espaços escolares e não escolares utilizados, os artefatos consumidos nas aulas, como também a natureza e uso desses objetos escolares no ato de ler, escrever e contar (Castellanos, 2017) posso afirmar que, mesmo sendo a cultura escolar "um conjunto de normas que definem conhecimentos a ensinar e condutas a inculcar, e um conjunto de práticas que permitem a transmissão desses conhecimentos e a incorporação desses comportamentos" (JULIA, 2001, p. 10), por outro lado, essa cultura que "absorve e impõe" não tem sido a mesma para todos e com todos, dependendo, em último caso, do que fazem os diferentes sujeitos protagonistas nos diversos lugares de ensino a partir de especificidades contextuais. Cultura escolar em plural ou culturas escolares que também se constituem a partir de um "conjunto dos conteúdos cognitivos e simbólicos que, selecionados organizados, 'normalizados', 'rotinizados', sob o efeito dos imperativos de didatização constituem habitualmente o objeto de uma transmissão deliberada no contexto das escolas" (FORQUIN, 1993, p. 167).

Nesse sentido, o objetivo aqui é problematizar os conteúdos que emergem de fontes documentais sobre a instrução primária no século XIX na Província do Maranhão à luz dos conceitos da teoria da cultura material escolar, sustentando-me nos aportes teórico-metodológicos da História Cultural (CHARTIER, 1990) e operacionalizando o fazer histórico em duas frentes: a revisão da literatura sobre a temática em questão e a localização, identificação e análise de fontes oriundas do Arquivo Público do Maranhão que me auxiliam na compreensão da cultura maranhense, da cultura escolar das instituições de ensino e da cultural material escolar por meio de leis, regulamentos, decretos, aprovações e veto. Registro as ações dos presidentes da Província e dos inspetores da instrução pública sobre as instituições de ensino local, identificando vestígios que exponham o poder de decisão dos gestores e os critérios em uso para abrir e fechar escolas, nomear e demitir professores, abrir concursos públicos, criar cadeiras e exigir métodos de ensino; práticas culturais específicas que dependem das estratégias de imposição e das táticas de apropriação que emergem no modelo polemológico de Certeau (2008). 


\section{Instrução Primária: entre atos e fatos administrativos}

No Maranhão, a expansão da escolaridade já vinha ocorrendo desde a aprovação da Lei de 15 de outubro de 1827, primeira e única lei geral sobre a instrução primária no Brasil imperial, que determinava a criação de escolas em todas as cidades, vilas e lugares mais populosos do Império, aumentando de 14 para 24 o número de escolas nesse período (VIVEIROS, 1953) ${ }^{1}$. Contudo, nas estatísticas apresentadas por Barroso (1867), em A Instrução Pública no Brasil, fica explícito o lugar que ocupava a província se comparada com o Norte, Nordeste e, mesmo com o Município $\mathrm{Neutro}^{2}$, num total de vinte províncias expostas $^{3}$. Segundo o autor, ao calcular o número de alunos por habitantes livres nas regiões, o Maranhão encontrava-se entre as oito primeiras, das quais o Norte e o Nordeste estavam representados somente por três ${ }^{4}$.

Na comparação do número de alunos nas escolas públicas e particulares de todas as localidades contempladas, a província ficou entre as nove primeiras, atendendo a mais de $10 \%$ da população escolar, juntamente com Alagoas, não se podendo explicar unicamente por meio dos aspectos econômicos e da imigração "[...] o maior ou menor atendimento escolar provincial; [já que] em algumas províncias [...] homens públicos se interessaram mais pelo problema de ensino que em outras" (PAIVA, 1987, p. 69); embora o número de indivíduos com idade escolar capazes de receber instrução em todo o país fosse de 1.190.000, só 104.025 foram instruídos contra uma população de 981.808 fora da escola,

1 Viveiros, em trabalho divulgado em diversas edições no jornal $O$ Combate em 1937, encontrou no livro de anotações do Liceu escriturado em 1838, que "de 14 escolas que tínhamos, passamos a 24: duas na capital e uma em Alcântara, Arari, Brejo, Caxias, Guimarães, Icatú, Mearim, Monção, Paço do Lumiar, Pastos-Bons, Pinheiro, Itapecuru, Rosário, S. Bento, S. João de Côrtes, S. Antonio das Almas, S. Vicente Férrer, S. Miguel, Tutóia, Vinhais, Viana e Vargem Grande" (VIVEIROS, 1953, p. 7).

2 Estatísticas copiladas "segundo o trabalho publicado recentemente pela Commissão Directora da Exposição Nacional, e intitulado O Império do Brasil na Exposição Nacional de 1867, em Paris, [onde] o total de alumnos de instrução primária em todas as Províncias, menos a de Matto Grosso, [era] de 107, 485" (BARROSO, 1867, p. 35, grifo do autor).

3 Amazonas, Pará, Maranhão, Piauí, Ceará, Rio Grande do Sul, Paraíba, Pernambuco, Alagoas, Sergipe, Bahia, Espírito Santos, Rio de Janeiro, São Paulo, Paraná, Santa Catarina, Rio Grande do Sul, Goiás, Minas Gerais e Município Neutro.

4 Entre as primeiras províncias contempladas estava o Paraná com 1 aluno para cada 31 habitantes (1/31) e o Município Neutro com 1/39; seguindo Espírito Santo e Rio Grande do Sul com 1/42 e 1/44 respectivamente; Santa Catarina com 1/51; e o Maranhão, o Pará e Alagoas com 1/55. Ver Barroso (1867, p. 35). 
isto é, no Brasil Imperial não se chegou a atender "[...] nem mesmo 9\% da população escolar calculada sobre os habitantes livres" (PAIVA, 1987, p. 67). Diversidade e forma desigual do processo de escolarização primária a nível local, regional e nacional, que nem por isso " $[. .$.$] devem nos levar a acreditar que a$ descentralização político-administrativa pelo Ato Adicional de 1834 acabou por impedir o desenvolvimento da instrução primária no Brasil imperial" (FARIA FILHO, 2007, p. 138).

É nesta tensão entre o local, o regional e o nacional, entre a cultura escolar protagonizada pelos regulamentos, reformas, prescrições e normas específicas de cada província, e as culturas escolares concebidas nas suas singularidades, desde uma perspectiva horizontal que se ramificam e dependem daquilo que os sujeitos atuantes são capazes de fazer com suas táticas de apropriação, que tem que ser analisada a cultura material escolar. É nesse equilíbrio de tensões estabelecido entre a cultura escolar mediatizada pelas pretensas estratégias de imposição que se direcionam verticalmente do exterior para o cerne da escola, do diretor dos estabelecimentos escolares para o interior da sala de aula, do professor para seus alunos via métodos de ensino e regras de controle/ ajustamentos, e as culturas escolares que se configuram partindo do nível de criatividade/inventividade dos sujeitos que tentam lidar com o imposto, que deve analisar-se o ensino primário maranhense dos oitocentos e suas formas de fazer como dispositivo de apropriação e consumo da cultura material da escola; compreendendo-a, sobretudo, no cerne da cultura interna de cada espaço educacional de acordo com os objetos e com as próprias práticas, uma vez que "é pela e na educação, através do trabalho paciente continuamente recomeçado de uma "tradição docente" que a cultura se transmite e se perpetua: a educação "realiza" a cultura como memória viva [...]" (FORQUIN, 1993, p. 14), o que implica que ao tentar-se compreender o ensino maranhense público primário, a escola e a relação desta última com a cultura, se destaque que esse espaço é "o local de convivência de culturas (infantis, juvenis, adultas, religiosas, étnicas, dentre outras)" (VIDAL; SCHWARTZ, 2010, p. 18), trazendo consigo a possibilidade de flagrar trajetórias indeterminadas de sujeitos diferentes com instrumentos culturais similares e a relação entre práticas distintas mediadas e norteadas não totalmente por prescrições e normas.

As ações políticas e administrativas em relação à instrução pública primária, manifestadas em documentos, serviram como referência para compreender os primeiros passos. As atas do Conselho Presidial do Maranhão ${ }^{5}$, instalado no

5 O Conselho Presidial também é chamado de Conselho Administrativo, Conselho de Presidência ou Conselho de Governo, tendo como objetivo tratar de questões governamentais especialmente as que demandassem exame e juízo administrativo. 
ano de 1825 até 1828 , ajudam este colegiado a se firmar como instituição política e normatizadora que legislava via pareceres e resoluções sobre os mais variados assuntos de interesse provincial; sobretudo aqueles referentes à instrução: informações e comunicados de conselheiros que apresentam ações, atos, fatos e datas determinando intenções, posições e normas. Este Conselho Presidial com base na lei de 15 de outubro de 1827, e segundo os prescritos na Carta de 20 de outubro de 1823, teve que instituir a instrução dos cidadãos maranhenses baseando-se no artigo 24 que definia como responsabilidade de cada Província "promover a educação da mocidade" e indicar por meio das atas diversas ações referentes à instrução local.

Entre os atos em registro, a modo de exemplo, posso citar as exigências do presidente da província (como gestor maior) e do inspetor da instrução pública para a utilização do método mútuo na instrução primária. A incorporação do método lancasteriano foi ordenado via dispositivo legal em 17 de dezembro de 1849, por Honório Pereira de Azeredo Coutinho, Presidente da Província:

Art. 1 ${ }^{\mathrm{a}}$. Os Professores Públicos de Primeiras Letras da Província servir-se-ão no ensino da mocidade do método individual, simultâneo, e lancastrino, segundo a frequência dos seus alunos mínima, media, e máxima marcada nos artigos seguintes, e fica isso fato dividido em três categorias... (MARANHAO, 1849).

O método de Lancaster ${ }^{6}$ foi uma estratégia utilizada em todas as províncias brasileiras e os materiais adquiridos de acordo com o estabelecido para sua implantação se constituiriam em objetos escolares que propagariam oficialmente o ensino por monitoração. Ensino que se instauraria por meio do alfabeto e dos livros de soletrar, mediados pelas séries de lições de leitura e do novo sistema de aritmética, na inculcação dos deveres para os decuriões e da explicação pelo método de ensinar em ordens, partindo do número de procedência para os círculos, do número de revistas, dos bilhetes dos decuriões e dos bilhetes de acusação e de vergonha.

No caso específico do Maranhão, este método seguiu em duas direções: uma aula aberta por Condurú para meninos, enquanto não estivesse "[...] montada a casa que para a mesma escola se mandou construir na Rua do Sol"

6 O sistema monitorial ou método Lancaster, como ficou mais conhecido no Brasil. Seus criadores foram Andrew Bell e Joseph Lancaster. 
(MARANHÃO, 1849), e a criação de uma Escola Normal de Ensino Mútuo7 , com a finalidade de capacitar professores efetivos para que implantassem este método em suas localidades, e os indivíduos que tivessem optado profissionalmente pelo magistério. Esta parece ter sido uma característica das Escolas Normais brasileiras que adotaram o ensino mútuo, como a do Rio de Janeiro, em 1835, e a da Bahia, em 1836 (VILLELA, 1999).

"Esses ares de nova luz sobre a educação maranhense" ${ }^{8}$ foram defendidos por intelectuais como João Lisboa, Gonçalves Dias e César Augusto Marques, que viam na proposta apresentada um "manancial de oportunidades para a instrução dos meninos desta província" (MARANHÃO, C., 1839). Apesar desse entusiasmo, os professores, como principais interessados nessa experiência pedagógica, não demonstraram vontade de se deslocarem do interior para a capital por um período de um ano "[...] para conhecerem a verdadeira essência do método" (MARANHÃO, D., 1839, p. 29), desconsiderando assim, o artigo $2 .^{\circ}$ da Lei $n .^{\circ} 76$, que determinava que todos por ele se instruíssem; mesmo com a atenuante do aumento da remuneração, já que o professor que em menos tempo "[...] se mostrasse praticamente perito no referido ensino pelos progressos, que fizerem seus alunos, [receberia a] mais, a quinta parte do seu ordenado" (CASTRO, 2009, p. 48)9.

As justificativas para o aparente desinteresse dos professores eram as mais diversas: as dificuldades financeiras das famílias, já que muitos deles tinham que se manter na capital e sustentarem esposas e filhos deixados no interior, como reclamara o professor Felipe Francisco Monteiro, da Vila de Santa Helena (MARANHÃO, C., 1844); a distância da capital, que tornaria inviável a permanência em São Luís por períodos longos; o afastamento dos professores, que poderia desestimular os alunos do interior ou influenciar os pais a procurarem outras escolas, levando ao fechamento dos espaços escolares já instituídos, como temia Jose Ladislau da Silva Raposo, da Vila de São João de Cortes (MARANHÃO, C., 1844); sem contar com as exigências às professoras por parte da família, do matrimônio e da maternidade, que provavelmente foram responsáveis pela sua omissão e não participação. Enfim, as preocupações dos professores se respaldavam nas condições econômicas e políticas do Maranhão que não propiciavam segurança e sustentos adequados, encontrando-se ainda sob os efeitos da Balaiada (1838-1841).

Em 1842, como forma de estimular o deslocamento dos professores do interior para São Luís, o Presidente da Província, João Antônio de Miranda,

7 Primeira iniciativa governamental de implantação de uma Escola Normal na província. 8 Expressão utilizada por Felipe Condurú para defender a importância da criação da Escola Normal. 9 Lei n. 76, de 24 de julho de 1838. 
determinara que os interessados em frequentar a Escola Normal receberiam uma gratificação para sua manutenção na capital, continuariam a receber integralmente seus vencimentos, teriam a garantia da reabertura das suas aulas quando concluíssem o curso, e, nas localidades onde havia um número maior de alunos, especificamente seriam contratados professores substitutos para garantir o não fechamento do espaço escolar; mas para os professores gozarem desse benefício, o delegado literário, ao qual o professor estava subordinado, tinha que comunicar a disponibilidade ao Inspetor da Instrução Pública, e este ao Presidente da Província.

As estratégias adotadas para incentivar a formação pedagógica na Escola Normal via método por monitoria não despertaram o interesse esperado nos professores; situação que obriga a Venâncio José Lisboa (Presidente da Província), em 1842, ordenar a frequência no referido curso de todos os professores que tivessem mais de 40 alunos matriculados, os quais perderiam seus vencimentos caso reagissem contrariamente, podendo ser despedidos das suas funções no âmbito da instrução pública se desconsiderassem as medidas impostas. Por outro lado, apesar das subsequentes críticas ao método, os governantes esperavam que, diante dos aspectos "pouco lisonjeiros da instrução pública" (MARANHÃO, D., 1841), se conseguisse por esse caminho minimizar os problemas do restrito acesso às escolas, notadamente no interior, onde a ausência de professores, prédios e de material escolar, entre outros fatores, eram mais acentuados que na capital.

O fascínio pela adoção do método lancasteriano, que os presidentes proferiam, em especial, Sousa e Melo (1838), Figueiredo Camargo (1839) e Antonio de Miranda (1841) estava aparentemente baseado na economia de dispêndios, uma vez que sua implantação propunha e simbolizava a contenção de despesas, quer com os pagamentos dos professores e no uso dos materiais da cultura escolar, quer com o ensino em massa de crianças nos rudimentos da leitura, escrita e cálculo, e com as lições dos preceitos morais e religiosos concebidos por meio da instrução pública num período mínimo de tempo (CASTELLANOS, 2017, p. 226).

Nesse sentido, tomo de empréstimo o conceito de cultura de Geertz (1989), para o qual o significado de nos tornarmos humanos e individuais se dá quando construímos, sob a direção dos padrões culturais, sistemas de significados criados historicamente, por meio dos quais ordenamos, objetivamos e direcionamos a nossa existência e as práticas culturais que nos legitimam, na medida em 
que a definição de homem não está dada nem pelas suas habilidades inatas ${ }^{10}$, nem por seu comportamento real ${ }^{11}$, mas sim pelo elo que existe entre eles, pela forma que o primeiro é transformado no segundo, pela maneira como as potencialidades genéricas são focalizadas nas atuações específicas numa teia de significados. Em outras palavras, assim como a cultura nos modelou e nos modela como espécie única até hoje, ela nos modela como indivíduos separados, constituindo-se nesta "dupla modelagem", o aspecto que temos em comum, "“[... nem um ser subcultural imutável, nem em consenso de cruzamento cultural estabelecido" (GEERTZ, 1989, p. 64), possibilitando este subterfúgio, o declínio da perspectiva uniformizante do homem que se tinha ao reconhecerem-se táticas de apropriação diferenciadas, e uma nova forma de entender a cultura quando se tenta compreender que "[...] o que o homem é pode estar tão envolvido com onde ele está, quem ele é e no que ele acredita, que é inseparável deles" (GEERTZ, 1989, p. 47); embora nos interesse enfatizar aqui as desigualdades e as diferenças nas formas de apropriação e nos usos das formas culturais no âmbito da instrução primária maranhense: um ser que vem-a-ser no ato de tecer significados e que constrói e vive sua história mediado pela própria ação num processo textualizador constante (HUNT, 1995).

Ações dos diferentes sujeitos em condições desiguais consideradas como contextos para a invenção que é permitida pela "liberdade condicionada e condicional" do habitus; "uma relação entre convenção e inovação" que se dá a partir do ato considerado como o " [...] comportamento moldado até certo ponto, pelas contingências do momento e seus requisitos estratégicos, e por considerações práticas" (BOURDIEU, 1996, p. 124). Ou seja, para além da teia de significados culturalmente produzidos no marco da instrução primária maranhense, os espaços e métodos, as leis e regulamentos, questiono a historicidade dessa rede, para compreender quem cria essa teia, quem define os significados culturais e com quais finalidades.

Nessa perspectiva, embora a cultura material escolar se conforme em três variáveis fundamentais para Lopes Martin (2006, p. 425): "o prédio, o mobiliário e o material de ensino"; para Escolano Benito (1990), a história da escolarização e dos objetos escolares não se reduz "à análise dos registros quantitativos em que se objetiva sua implantação institucional, senão que comporta o estudo de todas as condições em que se levou a cabo o processo de educação, desde os materiais, até as curriculares e metodológicas (ESCOLANO BENITO, 1990, p. 11). Dito de outra forma, a cultura material escolar está centrada "na relação humana com

10 Concepção que se sustentou no Iluminismo.

11 Como faz grande parte da ciência social contemporânea. 
o mundo material" (SOUZA, 2007, p. 169) expressa nas práticas educacionais, evidenciando os aspectos da organização escolar, os projetos pedagógicos de escolarização e as racionalidades pedagógicas, as representações da escola e os métodos de ensino, os dispositivos educativos e as intenções educacionais. Cultura material entendida como "o conjunto dos artefatos materiais em circulação e uso nas escolas, mediados pela relação pedagógica que é intrinsecamente humana, revelador da dimensão social” (PERES; SOUZA, 2011, p. 56), e não simples reflexo das relações sociais (VEIGA, 2000).

Faria Filho (2003, p. 8), por outro lado, afirma que a cultura escolar possibilita "articular, descrever e analisar, de uma forma muito rica e complexa, os elementos chave que compõem o fenômeno educativo, tais como os tempos, os espaços, os sujeitos, os conhecimentos e as práticas escolares". Assim, caracterizar a escola na perspectiva da cultura escolar e analisar seus instrumentos e uso segundo as necessidades e o sentido dado a eles é perceber que os recursos educacionais e sua evolução no processo de ensino-aprendizagem constituem-se em elementos da cultura material escolar. Com isso, pode-se dizer que cultura escolar é tudo aquilo que compõe a materialidade da escola, desde seus mínimos detalhes até suas grandes estruturas físicas.

Nessa ótica, é possível identificar com as mudanças nos regulamentos da instrução pública de 1844, 1854, 1874 e 1877, que acompanharam a dinâmica do ensino público primário, o que cada escola deveria conter, segundo o último regulamento elaborado neste período:

Um armário, três cadeiras (para o professor e pessoas que visitarem a escola) uma mesa para o professor e as pessoas que forem precisar, para os alunos, bancos para estes, um relógio, uma campainha, um quadro preto de madeira, esponja e giz para os exercícios aritméticos, uma coleção de pesos e medidas do sistema métrico decimal, traslados, lápis, canetas, penas, réguas para escrita, cabides para chapéus, potes e vasilhas menores para água, dois livros para matrículas dos alunos e para registro dos inventários dos objetos da escola, e tudo o mais que o inspetor da instrução pública julgar precioso (CASTRO, 2009, p. 32).

Nesse sentido, se faz importante captar os aspectos da cultura material escolar, como também os espaços escolares e seus usos que fazem parte da cultura escolar de cada instituição (JULIA, 2001) ou das culturas escolares (FORQUIM, 1993); pois é nestes suportes e no cosumo diferenciado de acordo com as necessidades do público alvo que podem encontrar-se ações e atos repletos de significados para aqueles que vivenciaram suas instalações num contexto 
específico; ou seja, a partir dessa materialidade torna-se possível compreender o sentido dado à cultura material escolar.

A falta de uniformes e de livros registrada na documentação como suportes da cultura material escolar igualmente é indicativo da situação das escolas na capital e no interior da província. Este vestígio aponta o imperioso da vestimenta para atender o contingente de "meninos de um e de outro sexo que por falta de meios não [tinham] podido frequentar a instrução primária, a fim de fornecer-lhes as roupas e os livros que lhes [fossem] indispensáveis" (MARANHÃO, R., 1874, grifo nosso), e para a devida garantia do ensino em crianças em idade escolar, constituindo-se isto responsabilidade do governo registrada em lei, que embora não se operacionalizasse nem se efetivasse na sua totalidade, mesmo assim se legitimara como dispositivo normativo para o funcionamento da instrução pública primária.

Um documento importante que retrata a situação das escolas maranhenses da capital na década de 1840 do oitocentos é o relatório de Casemiro Sarmento (Inspetor da Instrução Pública) ao visitar as três escolas da capital: da freguesia da Sé (meninos e meninas) e da Conceição. Sobre as aulas de primeiras letras de meninos da freguesia da Sé informava que tinha encontrado apenas 13 alunos, esfarrapados e imundos "e quase todos das últimas classes da sociedade, o que provão o pouco conserto que esta escola inspira" (MARANHÃO, O., 1849), sem contar com a falta de compêndios nem utensílios; "em suma não [tinha] a casa de instrução da mocidade mais que [o] nome" (MARANHÃO, O., 1849). A escola da freguesia da Conceição estava localizada em uma casa de aspecto desolador, na qual, "o esquio corredor em que se [dava] a aula não [era] arejado, não estava limpo, os meninos estão descuidados, um ou outro [tinha] compêndios velhos e sujos" (MARANHÃO, O., 1849). A última escola de meninas da freguesia da Sé estava alojada em uma sala sofrível, arejada e limpa; as alunas tinham onde se sentar, mas não onde escrever, a "não ser a pequena mesa da professora: compêndios, translados pouco vi", afirmando, por fim, que podia "assegurar que esta escola e como são todas as demais do país, no mais tudo que conseguem as meninas é aprender a soletrar e escrever mal e algumas poucas costuras" (MARANHÃO, O., 1849).

Uma questão que emerge deste relatório é: se as escolas da capital estavam nesse estado de penúria, como se encontrariam as do interior, principalmente das localidades mais afastadas de São Luís? Daí ser comum, nas correspondências dos professores e dos delegados literários, encontrar reclamações e pedidos de reformas e/ou construção de edifícios, de artefatos da cultura material escolar como bancos, mesas, potes, papéis, lápis, dentre outras, como faz o professor da Vila de Carolina, que reivindicava do governo o aluguel de uma casa e a compra de livros e compêndios para serem distribuídos aos alunos pobres 
(MARANHÃO, O., 1869). O professor da Vila de São Bento reclamava que em sua escola não havia quaisquer meios para o ensino das primeiras letras e solicitava os seguintes materiais, especificando os seus valores: dez bancos a 6 mil réis, dez bancos para servirem para a escrita a 11 mil, uma palmatória no valor de mil réis, um banco para potes a 5 mil réis e um armário para guardar os compêndios a 12 mil (MARANHÃO, O., 1869). Por sua vez, as professoras Rosa Cesarina de Amorim, da Vila de Rosário; Raimunda Joaquina Lopes, de Vargem Grande, e Joana Maria da Conceição, de Barra do Corda, faziam as mesmas solicitações, além dos mobiliários e livros, requerendo meios para poder ensinar o bordado e a costura às suas alunas (MARANHÃO, O., 1869).

Enfim, o quadro da instrução no Maranhão imperial pode ser melhor compreendido no relatório que apresenta José da Silva Maia (Inspetor da Instrução Pública) ao Presidente da Província João Silveira de Souza, em 5 de janeiro de 1861, no qual afirma que:

Em resumo a falta de utensílios, a prática seguida de lecionarem os professores em suas próprias casas que são pela maior parte acanhadas e não comportam o número dos matriculados, a falta de compêndios para serem distribuídos pelos alunos pobres, a mesquinhez dos ordenados dos professores, tudo isso tem exercido sobre o ensino uma influencia perniciosa e são estas as principais causas da marcha lenta e arrastada. As medidas, portanto, que proponho, tendentes a melhorar este importante ramo do serviço público são as seguintes: $1^{\circ}$ fornecimento de mobília para as escolas; $2^{\circ}$ casas próprias para as mesmas; $3^{\circ}$ compra de livros adotados para serem distribuidos aos alunos reconhecidamente pobres; $4^{\circ}$ aumento dos professores do interior (MARANHÃO, O., 1861, grifo nosso).

\section{O livro escolar como cultura material da escola}

Considerar o livro escolar também como artefato da cultura material da escola, segundo Castellanos (2017), significa dar-lhe um estatuto ao tentar flagrar na sua materialidade as reformas educacionais a que foi exposto, dependendo dos trâmites de aprovação, adoção e veto, as concepções pedagógicas às quais esteve vinculado, a relação com os diferentes tipos de escola a que foi destinado, que podem denunciar projetos de ensino e de formação para grupos de sujeitos específicos, e relacioná-lo com a expansão dos espaços escolares que está inscrita no quantitativo de remessas registradas no corpus documental; como 
igualmente nos permite captar as práticas de ensino que impunha dependendo de sua organização e conteúdo, a circulação de modelos educacionais expressos nas diferentes produções e edições, e a relação estabelecida entre os materiais, a indústria escolar e a escola como mercado (VIDAL; SILVA, 2011). Por outro lado, por meio do livro escolar concebido como parte da cultura material escolar, posso vislumbrar não só as experiências individuais e coletivas de construção de subjetividades, os esquemas perceptivos e os gostos, as corporeidades, as memórias e os afetos, na medida em que são igualmente passíveis de alcance a organização escolar, as finalidades sociais e culturais da escola, os posicionamentos discursivos entre alunos e professores, a relação entre os suportes e os métodos, a conformação dos espaços e dos tempos escolares como aspectos materiais do universo da escola, as estratégias didáticas, as ideologias impostas e a “[...] intromissão da indústria no universo escolar, não apenas como fornecedora [...]; mas também como produtora de novas necessidades impulsionando o comércio escolar" (VIDAL; SILVA, 2011, p. 23). Em outras palavras, o estudo do livro escolar pautado na "cultura material como elemento significativo de compreensão da apropriação social e da vida escolar" (SOUZA, 2011, p. 15).

Nesse sentido, conceber o livro utilizado no ensino como cultura material escolar me permite invadir o espaço interno da escola, já que ao analisar os processos de aprovação, adoção, distribuição e veto dos artefatos culturais e cruzá-los com outras fontes de naturezas diversas, comparando dados e criando alternativas metodológicas, posso distinguir a disciplinarização dos corpos, a conformação da corporeidade dos sujeitos em contato com os utensílios, a frequência aos espaços da escola, a instância econômica e a escolar, as inovações metodológicas; isto é, os indicadores de uma dada prática por meio dos objetos culturais em determinado contexto histórico, disputas que em torno do livro escolar e da materialidade da escola me permitem perceber como os projetos sociais e pedagógicos de educação foram construídos e as especificidades internas das políticas, dos projetos e das práticas pedagógicas. Enfim, quanto à inserção dos livros escolares na instrução, às reformas, aos programas de ensino, aos "[...] assuntos educacionais, a partir de 1834, nunca deixaram de ser controlados de forma centralizada, apesar da aparente descentralização legal" (BITTENCOURT, 2008, p. 54).

Dentre os vários documentos pesquisados, em especial as correspondências dos professores para os inspetores e destes para os presidentes de província, localizei um conjunto de fontes que me possibilitaram enxergar que a adoção dos livros foi ponto de discórdia entre o inspetor, os docentes, e os diretores dos estabelecimentos, em especial, aqueles das escolas particulares. Certamente isso acontecia por terem menor dependência financeira dos cofres provinciais, desejando maior autonomia nas escolhas dos artefatos de leitura e escrita, 
como o fazem os professores Alexandre José Rodrigues e Domingos Feliciano Marques Perdigão, diretores do Colégio de Nossa Senhora da Conceição e de Nossa Senhora dos Remédios, respectivamente (MARANHÃO, C., 1844d), que julgavam $A$ arte de aprender a ler a letra manuscrita, de Duarte Ventura, adotado pela Inspetoria da Instrução, uma obra que não tinha nenhuma aplicabilidade, já que "nas aulas de primeiras letras, quanto ao primeiro estabelecimento não existe um só exemplar e quanto ao segundo apenas cinco ou seis meninos leem por ele" (MARANHÃO, C., 1844c), havendo, além disso, a relutância dos pais de se negarem "[...] a uma tal exigência, chegando a certificar [aos citados diretores] que se [sentiam] constrangidos por eles e [coagidos] a apresentar a seus filhos semelhante Livro" (MARANHÃO, C., 1844c).

A polêmica na indicação e adoção dos livros escolares ganha maior destaque quando a imprensa passa a publicá-la, expondo a rivalidade entre Casemiro José M. Sarmento, diretor da Instrução Pública, e Domingos Feliciano Marques Perdigão, diretor do Colégio Nossa Senhora dos Remédios.

De todos os professores particulares que há na Província, Domingos Feliciano Marques Perdigão é ónico que tem constantemente recalatrando as ordens, que em desempenho do meu cargo e em execução das Leis e Regulamentos, lhe hei transmitido, vindo somente a cumpri-la depois de grandes delongas e de polêmicas e constatações, nas quais ele tem sempre excedido as raias do decoro, do respeito e até da urbanidade, que ele me deve, como Inspetor da Instrução e por conseqüência seu superior, visto que pela Lei sou obrigado a velar na sua conduta, método de ensino, e bem assim no tocante a matricula, compêndios, remessa de mapas e castigos [...]. Isto que é público e notório nesta cidade, bastava para dar a conhecer aquele Diretor, mas ele não quis dar uma prova contra si e por isso tem continuado a mostrar-se insubordinado, rebelde e descomedito contra a lei e contra a quem em seu respeitável nome se lhe tem dirigido (MARANHÃO, C., 1844e, grifo nosso).

As reivindicações de Feliciano Perdigão (Diretor do Colégio dos Remédios) encontram apoio em outros professores particulares, na medida em que Casemiro Marques pede ao Vice-Presidente da Província, Ângelo Carlos Muniz, que “[...] Vossa Excelência obstante assim como os demais professores particulares, a execução sem excitação as minhas ordens legais" (MARANHÃO, C., 1844e), e ainda denuncia que os professores particulares, sob a mesma inspeção pública, estavam a dar-lhe "conselho e [propor-lhe] transações acerca dos preceitos que lhe [dava] no tocante a objetos em que estão eles sujeitos à mesma inspeção" 
(MARANHÃO, C., 1844d). Julgava o Inspetor da Instrução Pública que o mais grave era "escarnecer-me, como o fazem, dando escândalos na frente dos seus demais colegas" (MARANHÃO, C., 1844d), e servindo de mau exemplo à mocidade entregue aos seus cuidados, "que nutrida com tal leite, não pode deixar de ser insubordinada e obstinada para o futuro, por conseqüência de causar graves danos à sociedade" (MARANHÃO, C., 1844d).

Feliciano Perdigão, se por um lado alegava que o inspetor perseguia o seu estabelecimento, impedindo de adotar os compêndios que achasse mais adequados para os diferentes níveis de aproveitamento discente e de estabelecer um plano de estudo que norteasse as dificuldades encontradas no público alvo; por outro, denunciava que a insistência do Inspetor da Instrução de que as escolas maranhenses públicas e privadas adotassem o Catecismo, de Fleury, se fundamentava não essencialmente em aspectos pedagógicos, senão no fato de ser ele o tradutor da obra, obtendo autorização para adotá-la em todas as aulas de primeiras letras e, consequentemente, ter lucrado com sua divulgação, adoção e consumo.

A disputa entre o diretor do Colégio e o Inspetor da Instrução acirrase quando Perdigão passa a não adotar nenhum "dos livros, compêndios e traslados designados [...] para serem lidos em todas as Escolas da província" (MARANHÃO, C., 1844d). Em sendo assim, Casemiro Sarmento recorre aos dispositivos legais que "regulam a instrução pública sob as penas fulminadas contra os seus contraventores, que no caso vertente são de desobediência e de se lhe mandar fechar a aula" (MARANHÃO, C., 1844d), caso não recuasse da sua decisão. Segundo o inspetor, não adiantaria que o diretor se queixasse "ao Delegado de que os pais não [queriam] comprar os ditos compêndios", quando a lei assim o exigia e tinha que ser cumprida, advertindo que depois de oito dias estaria indo visitar e examinar o Colégio para verificar se suas instruções tinham sido cumpridas, do contrário mandaria fechar as suas aulas como o legitimava o Regulamento da Instrução Pública. As pendengas entre os dois, depois de três meses (outubro a dezembro), foram resolvidas no gabinete pelo Presidente da Província, Ângelo Carlos Muniz, quando exige que as obras adotadas nas demais escolas fossem usadas no Colégio de Nossa Senhora dos Remédios e que adotasse outras convenientes que não oneraram as famílias ao adquiri-las (MARANHÃO, C., 1844f).

Os problemas da instrução maranhense, mesmo com a criação da Inspetoria e a expansão das aulas em todas as cidades e vilas mais populosas no decorrer do império, não passam por alterações significativas, apesar dos inúmeros dispositivos legais (leis, regulamentos e estatutos) que buscam (de uma forma ou outra) sanar os problemas com a falta de professores e os baixos salários, com a ausência de prédios para o funcionamento das aulas (mesmo na capital), onde 
muitos funcionavam em igrejas, no subsolo dos órgãos públicos ou em casa alugadas pelos docentes, com a falta de material escolar para o desenvolvimento das atividades pedagógicas, com a ausência de livros escolares que comportassem o número de alunos nas escolas, comprometendo a uniformidade do ensino e a sistematização dos métodos. Dito de outra forma, o campo de estudos da cultura material escolar me possibilita problematizar estes aspectos materiais, que "[ [...] não somente [são] os objetos e as práticas culturais, mas também as condições de trabalho dos professores e de escolarização das crianças" (VEIGA, 2018, p. 31); carência, escassez e insuficiência quase naturalizada pela história que provoca indagações sobre as necessidades, as satisfações e "[...] a invenção da categoria aluno pobre para a identificação da clientela escolar" (VEIGA, 2018, p. 34).

No interior da Província, as escolas geralmente funcionavam nas residências dos professores, que tinham que dividir os afazeres domésticos com as lições dos alunos, impedindo que desenvolvessem com qualidade as suas atividades de ensino, "não [podendo] haver ordem, decência, e regularidade nessa casa de educação" (MARANHÃO, C., 1847). As reclamações durante todo este período vão permanecer segundo a análise realizada dos relatórios dos inspetores da Instrução Pública e dos presidentes de província, e são recorrentes até a República. A falta de mobília, como outro aspecto a ser tratado, por ser um dos impeditivos principais para o desenvolvimento do ensino, refletia-se nas reivindicações feitas ao governo por meio das decisões pessoais dos "professores que vendo que não [eram] atendidos nas suas justas reclamações [abriam] as suas escolas sem um só móvel. Outros se [servindo] de mobília emprestada e imprópria" (MARANHÃO, R., 1855) para os fins do ensino, que embora resultassem na garantia de um espaço de instrução, dando oportunidades às crianças em idade escolar, resultava também que grande parte dos alunos ficassem em pé ou sentados no chão, como acontecia na Vila de Viana.

Com relação aos compêndios escolares, entendo que apesar da entrada, tradução e impressão de inúmeras obras no Maranhão, o acesso dos alunos ocorreu de forma mais direta em São Luís e nas cidades mais prósperas como Alcântara, Caxias e Itapecuru. Nas outras localidades, nas escolas abertas em pequenos povoados e vilarejos, segundo o estabelecido em lei desde 1827 no território nacional, as obras, quando chegavam, não atendiam ao quantitativo de matriculados, sendo quantificado como exemplo excepcional, talvez $O$ Livro do Povo, que pela grande tiragem da obra, pela distribuição gratuita do autor, pelos preços módicos para seu acesso e pelas estratégias tomadas para sua distribuição alcançou toda a província, embora não a todos os alunos, como se depreende da análise das correspondências em que os professores ou os delegados literários agradecem o recebimento do livro ou pedem um número maior para que todas as crianças das Vilas pudessem ter um para si. 
Até aqui, a explanação sobre os livros utilizados no ensino da instrução primária no Maranhão Império, especificamente, sobre os livros escolares como cultura material da escola, tem sido sustentada nos procedimentos de aprovação, adoção e distribuição das obras, nos métodos expostos e nas temáticas abordadas nos exemplares estrangeiros, nacionais e/ou locais, indicados ou não, segundo os regulamentos e as leis impostas. Tem sido igualmente ancorada segundo o perfil dos autores, a qualidade dos livros e as formas de aplicação e avaliação dos assuntos na sala de aula dependendo do olhar do professor, da supervisão do delegado literário e da orientação do Inspetor da Instrução Pública.

\section{Conclusão}

À guisa de conclusão, posso afirmar que a normatização e o controle, mesmo com a descentralização instituída em lei, nunca deixaram de existir ao serem transvestidos em várias frentes, entre elas: nas nomeações dos presidentes pelo Governo Central e da subordinação do corpo coeso de políticos aos seus ditames nas diferentes localidades; na abertura de várias escolas públicas e particulares que se regiam por dispositivos legais similares entre todas as regiões; nas exigências dos artefatos da cultura material escolar, entre eles, os livros escolares utilizados na instrução seguindo critérios avaliativos que respondiam aos programas específicos do ensino e das disciplinas focalizadas nos princípios de moralidade e de civilidade; os métodos de ensino, embora as necessidades materiais para sua efetivação não fossem supridas pelo poder provincial; e a exigência do uniforme escolar via dispositivo legal e o descumprimento do próprio governo legitimando a ilegalidade; assim como, por meio das leis e dos regulamentos estabelecidos no cenário maranhense em concordância com os preceitos legais de outras províncias e do Município Neutro; isto é, "as reformas (e projetos de reformas) da instrução no Brasil em relação ao nível elementar, discutidas em nível de Parlamento Nacional, referiam-se unicamente ao Município na Corte [tornando-se] conhecidas em todo o país [e orientando] as iniciativas provinciais" (PAIVA, 1987, 69).

Enfim, mesmo que as limitações possam ser superadas quando falamos do ensino primário maranhense no Império, ao cruzar os dados expostos nos relatórios dos presidentes de província com os relatórios dos inspetores da instrução pública, e mesmo nos anúncios, denúncias e críticas inscritas no jornal, é importante frisar que se "a cultura material escolar está enraizada na própria forma escolar de escolarização” (SOUZA, 2007, p. 174), então não 
será possível pensar a escola nem os artefatos nela utilizados para além dos saberes construídos e das práticas realizadas, nem imaginá-la "descolada da sua dimensão material” (PERES; SOUZA, 2011); na medida em que "quem reflete sobre as aprendizagens escolares não pode abstraí-las totalmente das condições 'materiais' de sua realização" (CHARTIER, A. 2007, p. 45).

\section{REFERÊNCIAS}

BARROSO, José L. A instrução pública no Brasil. Rio de Janeiro: B. L. Garnier, 1867. BITTENCOURT, Circe M. F. Livro didático e saber escolar: 1810-1910. Belo Horizonte: Autêntica, 2008.

BOURDIEU, Pierre. Razões práticas: sobre a teoria da ação. $11^{\mathrm{a}}$ ed. São Paulo: Papirus editora, 1996.

CASTELLANOS, Samuel Luis V. O livro escolar no Maranhão Império. São Luís: EDUFMA; Café \& Lápis, 2017.

CASTEllanOS, Samuel Luis V. Sociedade Onze de Agosto: uma instituição de ensino popular no Maranhão Império (1870-1876). In: PINHEIRO, Antonio Carlos F.; MADEIRA, Maria das Graças de L. (org.). Instituições escolares e escolarização no nordeste. São Luís: EDUFMA; Café \& Lápis; João Pessoa: UFBP, 2011.

CASTRO, Cesar Augusto (org.). Leis e regulamentos da Instrução Pública no Maranhão Império: 1835-1889. São Luís: EDUFMA, 2009.

CERTEAU, Michel de. A invenção do cotidiano. Artes de Fazer. Petrópolis : Vozes, 2008.

CHARTIER, Anne-Marie. Exercícios escritos e cadernos de alunos: reflexões sobre práticas de longa duração. In: CHARTIER, Anne-Marie. Práticas de Leitura e escrita. História e atualidade. Belo Horizonte: Ceale Autêntica, 2007. (Coleção Linguagem e Educação).

CHARTIER, Roger. A história cultural: entre práticas e representações. Lisboa: Difel, 1990.

ESCOLANO BENITO, Agustín. Presentación. In: GABRIEL, Narciso de. Leer, escribir y contar. Escolarización popular y sociedade en Galicia (1875-1900). A Coruña: Ediciones de Castro, 1990.

FARIA FILHO, Luciano M. Instrução elementar no século XIX. In: LOPES, Eliana M. T.; FARIA FILHO, Luciano M.; VEIGA, Cynthia G. 500 anos de educação no Brasil. 3 ed. Belo Horizonte: Autêntica, 2007. 
FARIA FILHO, Luciano M. O processo de escolarização em Minas Gerais: questões teórico-metodológicas e perspectivas de pesquisa. In: VEIGA, Cynthia G.; FONSECA, Thais N. de L. (org.). História e historiografia da educação Brasileira. Belo Horizonte: Autêntica, 2003.

FORQUIN, Jean-Claude. Escola e Cultura: a sociologia do conhecimento escolar. Porto Alegre: Artes Médicas, 1993.

GEERTZ, Clifford. A interpretação das Culturas. Rio de Janeiro: Editora Guanabara Koogan, 1989.

HUNT, Lynn. A nova história cultural. São Paulo: Martins Fontes, 1995. Apresentação.

JULIA, Dominique. A cultura escolar como objeto historiográfico. Revista Brasileira de História da Educação, São Paulo, nº 1, p. 9-44, 2001.

LÓPEZ MARTIN, Ramón. El utilaje escolar y la segunda mitad del siglo XIX. In: ESCOLANO BENITO, Agustín (dir.). Historia ilustrada de la escuela en España: dos siglos de perspectiva histórica. Madrid: Fundación Germán Sánchez Ruipérez, 2006.

PAIVA, Vanilda P. Educação popular e educação de adultos. São Paulo: Edições Loyola, 1987.

PERES, Eliane; SOUZA, Gizele de. Aspectos teóricos-metodológicos da pesquisa sobre cultura material escolar: (im)possibilidades de investigação. In: CASTRO, Cesar Augusto (org.). Cultura material escolar: a escola e seus artefatos (MA, SP, PR, SC e RS, 1870-1925). 2. ed. São Luís: EDUFMA; Café \& Lápis, 2011.

SOUZA, Rosa Fátima de. História da Cultura Material Escolar: um balanço inicial. In: BENCOSTTA, Marcus Levy (org.). Culturas escolares, saberes e práticas educativas: itinerários históricos. São Paulo: Cortez, 2007.

SOUZA, Rosa Fátima de. Prefácio. In: CASTRO, Cesar Augusto (org.). Cultura material escolar: a escola e seus artefatos (MA, SP, PR, SC e RS, 1870-1925). 2. ed. São Luís: EDUFMA; Café \& Lápis, 2011.

VIDAL, Diana G.; SILVA, Vera Lucia G. da. Por uma história sensorial da escola e da escolarização. In: CASTRO, Cesar Augusto (org.). Cultura material escolar: a escola e seus artefatos (MA, SP, PR, SC e RS, 1870-1925). 2. ed. São Luís: EDUFMA; Café \& Lápis, 2011.

VIDAL, Diana G; SCHWARTZ, Cleonara M. (org.). História das culturas escolares no Brasil. Vitória, ES: EDUFES, 2010.

VILLELA, Heloisa de O. S. O ensino mutuo na origem da primeira escola normal do Brasil. In: BASTOS, Maria Helena C.; FARIA FILHO, Luciano M. de. A escola elementar no século XIX: o método monitorial/mútuo. Passo Fundo: EDIUPF, 1999.

VIVEIROS, Jerônimo de. Apontamentos para a história da instituição pública e particular do Maranhão. Revista de Geografia e História, São Luís, v. 4, p. 3-43, dez, 1953. 
VEIGA, Cynthia G. A história da escola como fenômeno econômico:diálogos com história da cultura material, sociologia econômica e história social. In: SILVA, Vera Lucia G.; SOUZA, Gizele de; CASTRO, Cesar A. (org.). Cultura material escolar em perspectiva histórica: Escritas e possibilidades. Vitória: EDUFES, 2018.

VEIGA, Cynthia G. Cultura material escolar no século XIX, Minas Gerais. In: CONGRESSO BRASILEIRO DE HISTÓRIA DA EDUCAÇÃO, 1., Rio de Janeiro, 2000. Anais [...]. Rio de Janeiro: SBHE, 2000. Disponível em: http://www.sbhe.org.br/ node/82. Acesso em: maio 2011.

\section{Fontes históricas}

MARANHÃO. Atas do Conselho do Governo da Província do Maranhão. Livro 1337. Arquivo Público do Estado do Maranhão. Setor de Códices, 1849.

MARANHÃO. Correspondência de Francisco Sotero dos Reis (Inspetor da Instrução Pública) enviada a Vicente Tomaz Pires de Figueiredo Camargo (Presidente da Província) datada de 22 de janeiro de 1839 .

MARANHÃO. Correspondência de Francisco Sotero dos Reis (Inspetor da Instrução Pública) a Venâncio José Lisboa (Presidente da Província), datada de 17 de janeiro de 1842.

MARANHÃO. Correspondência de Casemiro José M. Sarmento (Inspetor da Instrução Pública) a Jerônimo Martiniano Figueira Melo, Presidente da Província, datada de 1 de fevereiro de 1844a.

MARANHÃO. Correspondência de Casemiro José M. Sarmento (Inspetor da Instrução Pública) a Jerônimo Martiniano Figueira Melo, Presidente da Província, datada de 6 de março de $1844 \mathrm{~b}$.

MARANHÃO. Correspondência do Inspetor de Instrução Pública Casemiro José de M. Sarmento, ao Presidente da Província, João José Moura Magalhães, sobre a recusa do professor e proprietário do Colégio Nossa Senhora da Conceição, Alexandre José Rodrigues, em atender às determinações do inspetor, datada em $1^{\circ}$ de outubro de $1844 \mathrm{c}$.

MARANHÃO. Correspondência do Inspetor da Instrução Pública Casemiro José de M. Sarmento, ao Presidente da Província, João José de Moura Magalhães, sobre os professores Alexandre José Rodrigues e Domingos Feliciano Marques Perdigão, que não atendiam às exigências da inspetoria, datada em 2 de outubro de 1844 d.

MARANHÃO. Correspondência do Inspetor de Instrução Pública, Casemiro José de M. Sarmento, ao Vice-Presidente da Província, Ângelo Carlos Muniz, sobre a recusa do professor e proprietário do Colégio Nossa Senhora dos Remédios, Domingos Feliciano Marques Perdigão em atender as determinações do inspetor, datada em 16 de outubro de 1844 e (grifo meu). 
MARANHÃO. Correspondência do Inspetor de Instrução Pública, Casemiro José de M. Sarmento, ao Vice-Presidente da Província, Ângelo Carlos Muniz, sobre a recusa do professor e proprietário do Colégio Nossa Senhora dos Remédios, Domingos Feliciano Marques Perdigão em atender as determinações do Inspetor, datada em 31 de dezembro de $1844 \mathrm{f}$.

MARANHÃO. Correspondência de Sotero dos Reis, Inspetor da Instrução Pública, a Joaquim Franco de Sá, Presidente da Província, datado de 13 de setembro de 1847.

MARANHÃO. Discurso que proferiu o Exmº. Sr. Manoel Felisardo de Sousa e Mello, Presidente desta Província, na ocasião de abertura da Assembleia Legislativa Provincial, no dia 3 de maio do corrente ano. Maranhão: Tipografia de I. J. Ferreira, 1839.

MARANHÃO. Fala dirigida pelo Exmo. Presidente da Província do Maranhão, Herculano Ferreira Penna, à Assembleia Legislativa Provincial, por ocasião de sua instalação no dia 14 de outubro de 1849. Maranhão, Impresso na Typ. de J. A. G. de Magalhães, 1849. MARANHÃO. Discurso feito pelo Exmº . Sr. Dr. João Antonio de Miranda, Presidente da Província do Maranhão, na abertura da Assembleia Legislativa Provincial, no dia 3 de julho de 1841. Maranhão: Tipografia Monárquica Constitucional de F. de S. N. Cascaes, 1841.

MARANHÃO. Relatório enviado por Caetano José da Silva, Inspetor da Instrução Pública, para Eduardo Olimpio Machado, Presidente da Província, datado de 11 de abril de 1855 .

MARANHÃO. Relatório pelo Inspetor da Instrução Pública, José da Silva Maia, para o Presidente de Província, João Silveira de Souza, datado de 5 de janeiro de 1861.

MARANHÃO. Regulamento da Instrução pública de 1874.

MARANHÃO. Ofício enviado por Casemiro José de M. Sarmento (Inspetor da Instrução Pública) para o Presidente da Província, Herculano Ferreira Penna, em 16 de abril de 1849.

MARANHÃO. Ofício enviado pelo Inspetor da Instrução Pública, José da Silva Maia, para o Presidente da Província, João Silveira de Souza, em 3 de maio de 1869.

Texto recebido em 10/01/2020.

Texto aprovado em 16/04/2020. 